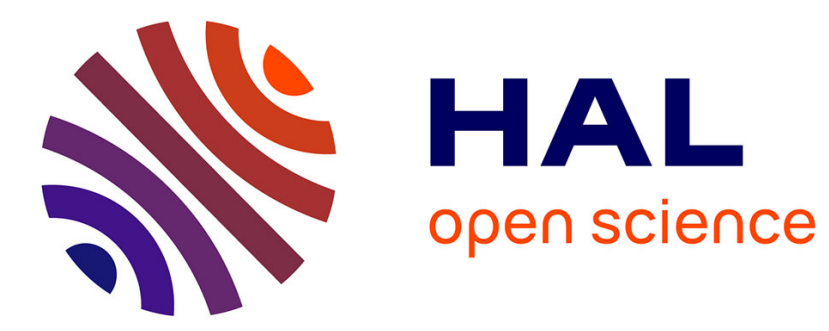

\title{
Some LPV Approaches for Semi-active Suspension Control
}

\author{
Olivier Sename, Anh Lam Do, Charles Poussot-Vassal, Luc Dugard
}

\section{To cite this version:}

Olivier Sename, Anh Lam Do, Charles Poussot-Vassal, Luc Dugard. Some LPV Approaches for Semiactive Suspension Control. ACC 2012 - American Control Conference, Jun 2012, Montréal, Canada. pp.n/a. hal-00682130

\section{HAL Id: hal-00682130 https://hal.science/hal-00682130}

Submitted on 23 Mar 2012

HAL is a multi-disciplinary open access archive for the deposit and dissemination of scientific research documents, whether they are published or not. The documents may come from teaching and research institutions in France or abroad, or from public or private research centers.
L'archive ouverte pluridisciplinaire HAL, est destinée au dépôt et à la diffusion de documents scientifiques de niveau recherche, publiés ou non, émanant des établissements d'enseignement et de recherche français ou étrangers, des laboratoires publics ou privés. 


\title{
Some LPV Approaches for Semi-active Suspension Control
}

\author{
Olivier Sename ${ }^{1}$, Anh-Lam Do ${ }^{1}$, Charles Poussot-Vassal ${ }^{2}$ and Luc Dugard ${ }^{1}$
}

\begin{abstract}
This tutorial paper aims at presenting two methodologies to deal with the semi-active suspension control problem, in the framework of Linear Parameter Varying (LPV) systems.
\end{abstract}

\section{INTRODUCTION}

The suspension system is a key element of the vehicle dynamics since it actually links the tires to the vehicle chassis. The characteristics of the suspension components (spring and damper) then influence the passenger comfort (through the vibration isolation) and the safety or road holding (through the wheel rebound).

This paper is concerned with controlled semi-active suspensions (such as Magneto-Rheological dampers) that have been more and more studied in the latter decade since they allow for varying damping rate (thus performance adaptation) and provide an interesting compromise between cost and performance compared to passive and active suspensions. The control challenge stands in the ability of taking into account the dissipativity of the damper [1]. If not handled the referred to as "clipped strategy" is necessary to saturate the control input [2], without any guarantee of performances.

In this tutorial paper, two control methodologies that handle the inherent limitations of the damper are described in the LPV framework. In the first one, a "smart" parameter is introduced allowing to take the real abilities of the damper into account, representing in some sense the excess of active control [3]. A scheduling parameter is indeed defined as the difference between the real controlled damper force and the required one given by the controller. In the second one, an LPV model is written from a quarter-car vehicle model including a non linear semi-active damper model [4]. From this LPV model, the dissipativity constraint of the semiactive damper is brought into the problem of input saturation. This latter problem is actually solved by integrating the saturation constraint as a new scheduling parameter. The advantage of this method is that the control input always meets the saturation constraint and hence the dissipativity constraint is fulfilled.

Both LPV controllers are designed using the well-known results given in [5] and [6].

*This work was supported by the French national project INOVE/ ANR 2010 BLAN 0308

${ }^{1}$ O. Sename, A-L. Do and L. Dugard are with GIPSA-lab, Control Systems Dept, CNRS-Grenoble INP, ENSE3, BP 46, F-38402 St Martin d'Hères cedex, France olivier.senamegipsa-lab.grenoble-inp.fr

${ }^{2}$ C. Poussot-Vassal is with Onera - The French Aerospace Lab, F-31055 Toulouse, France, Charles.Poussot-Vassal@onera.fr

\section{CONTROL-ORIENTED MODELS OF MR DAMPERS}

Magneto-Rheological (MR) dampers use MR fluids whose properties can be changed through the application of a magnetic field. Their advantages are a fast time response as well as a stable hysteretic behavior over a broad range of temperature, and a low battery voltage consumption. The modeling of MR dampers is a challenging problem because of the highly nonlinear behavior such as the bi-viscosity, the temperature dependency and specially the hysteresis. Here, the following model will be used for simulation of the real MR damper behavior [7]:

$$
\begin{array}{r}
F_{\text {damper }}=C_{1} \tanh \left(C_{2} \dot{x}_{m r}+C_{3} x_{m r}\right)+C_{4} \dot{x}_{m r}+C_{5} x_{m r} \\
+C_{6} \ddot{x}_{m r}+C_{7} I \tanh \left(C_{8} \dot{x}_{m r}+C_{9} x_{m r}\right)
\end{array}
$$

The parameters of the model (1) have been identified (see [7]) on the test-rig at Metalsa ${ }^{1}$ and are given in Tab. I. It is worth noticing that the coefficients in compression $\left(\dot{x}_{m r}<0\right)$ and extension $\left(\dot{x}_{m r} \geq 0\right)$ modes are different to better model the non-symmetric characteristics.

TABLE I

PARAMETER VALUES OF MR DAMPER (FOR SIMULATION)

\begin{tabular}{llll}
\hline Parameter & $\dot{x}_{m r} \geq 0$ & $\dot{x}_{m r}<0$ & Unit \\
$C_{1}$ & 128.5 & -128.6 & {$[N s / m]$} \\
$C_{2}$ & 412.2 & -489 & {$[N / m]$} \\
$C_{3}$ & 83.5 & -204 & {$[N]$} \\
$C_{4}$ & 608.8 & 611.5 & {$[N]$} \\
$C_{5}$ & 5457.6 & -2855.4 & {$[s / m]$} \\
$C_{6}$ & 3.9 & 4.2 & {$[1 / m]$} \\
$C_{7}$ & 484.3 & 484.3 & {$[1 / m]$} \\
$C_{8}$ & 6.5 & 6.5 & {$[1 / m]$} \\
$C_{9}$ & 3.4 & 3.4 & {$[1 / m]$} \\
\hline
\end{tabular}

\section{A. Controlled-oriented model 1}

While the nonlinearity of the damper should be taken into account in the controller design, many studies have considered a simple linear model of the damper:

$$
F_{\text {damper }}=c \dot{z}_{\text {def }}
$$

where $c$ is the varying damping coefficient and limited by $\left[c_{\min }, c_{\max }\right]$. Moreover, the damper force must be limited by a maximal value, i.e $\left|F_{\text {damper }}\right| \leq F_{\max }$ where $F_{\max }>0$, as shown in Tab. II from the real MR damper.

\footnotetext{
${ }^{1}$ www.metalsa.com.mx
} 
TABLE II

PARAMETER VALUES OF DAMPER - CONTROL ORIENTED MODEL 1

\begin{tabular}{lll}
\hline Parameter & Value & Unit \\
$c_{\text {min }}$ & 881 & {$[N s / m]$} \\
$c_{\max }$ & 7282 & {$[N s / m]$} \\
$F_{\max }$ & 1400 & {$[N]$} \\
\hline
\end{tabular}

\section{B. Controlled-oriented model 2}

While the model (1) approaches very well the behavior of a real MR damper, it is unnecessarily complex for control design. In [4], a simpler control-oriented model has been proposed as follows:

$$
F_{\text {damper }}=c_{0} \dot{x}_{m r}+k_{0} x_{m r}+f_{I} \tanh \left(c_{1} \dot{x}_{m r}+k_{1} x_{m r}\right)
$$

where $f_{I}$ is the controllable force which varies according to the electrical current $I$ in the coil $\left(0 \leq f_{\text {Imin }}<f_{I} \leq f_{\text {Imax }}\right)$. In general, $f_{I}$ can be any positive and invertible function of $I$, as the simple linear one:

$$
f_{I}=y_{m r} I
$$

where $y_{m r}$ is also a constant parameter. The model (3) whose parameters are given in Tab. III reflects the realistic behavior of an MR damper and approaches better the realistic MR damper model (1) and allows to fulfill the passivity constraint of the semi-active damper and introduces a control input $f_{I}$ (or I). As shown in Fig. 1, it well presents the bi-viscous and hysteretic characteristics of the damper, particularly the dependency on the input current.

TABLE III

PARAMETER VALUES OF DAMPER - CONTROL ORIENTED MODEL 2

\begin{tabular}{lll}
\hline Parameter & Value & Unit \\
$c_{0}$ & 810.78 & {$[N s / m]$} \\
$k_{0}$ & 620.79 & {$[N / m]$} \\
$f_{\text {Imin }}$ & 0 & {$[N]$} \\
$f_{\text {Imax }}$ & 800 & {$[N]$} \\
$c_{1}$ & 13.76 & {$[s / m]$} \\
$k_{1}$ & 10.54 & {$[1 / m]$} \\
$y_{\text {mr }}$ & 457.04 & {$[N / A]$} \\
\hline
\end{tabular}

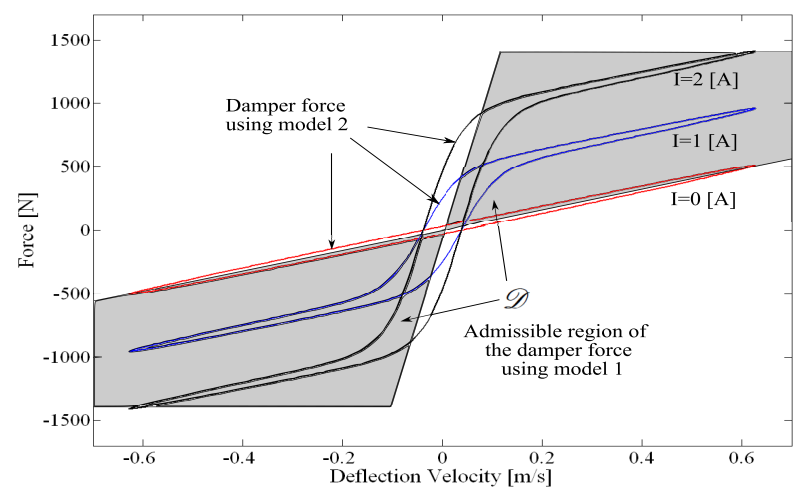

Fig. 1. Force vs Velocity characteristics of the damper model 2 with different current values $I$ and admissible region of the damper model 1

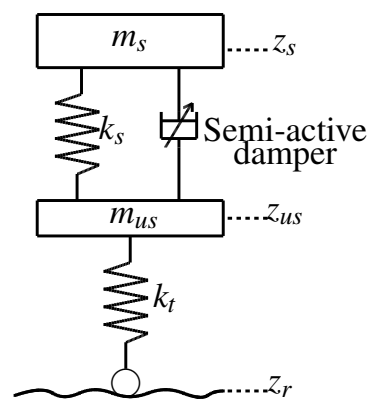

Fig. 2. Model of quarter vehicle with a semi-active damper.

In what follows, two control methods will be proposed according to the considered model (2) or (3). The validation of the control method will then be assessed in simulation using the realistic nonlinear model (1).

\section{Application In AUtomotive SUSPEnsion SYSTEMS}

\section{A. Quarter-car model}

One of the most well-known applications of semi-active dampers in industry is the automotive suspension system. To study the vertical dynamics of a car, i.e comfort and road holding, the simple quarter vehicle, depicted in Fig. 2, is usually considered. In this model, the quarter vehicle body is represented by the sprung mass $\left(m_{s}\right)$ and the wheel and tire are represented by the unsprung mass $\left(m_{u s}\right)$. They are connected by a spring with the stiffness coefficient $k_{s}$ and a semi-active damper. The tire is modeled by a spring with the constant stiffness coefficient $k_{t}$. As seen in the figure, $z_{s}$ (respectively $z_{u s}$ ) is the vertical displacement around the equilibrium point of $m_{s}$ (respectively $m_{u s}$ ) and $z_{r}$ is the variation of the road profile. It is assumed that the wheelroad contact is ensured. The dynamical equations of a quarter vehicle are given by

$$
\left\{\begin{array}{l}
m_{s} \ddot{z}_{s}=-F_{\text {spring }}-F_{\text {damper }} \\
m_{u s} \ddot{z}_{u s}=F_{\text {spring }}+F_{\text {damper }}-F_{\text {tire }}
\end{array}\right.
$$

where $F_{\text {spring }}=k_{s} z_{\text {def }}$ is the dynamical spring force, $F_{\text {tire }}=$ $k_{t}\left(z_{u s}-z_{r}\right)$ is the dynamical tire force and $F_{\text {damper }}$ is the damper force. Let us denote $z_{d e f}=z_{s}-z_{u s}$ the damper deflection. In this study, the model parameters correspond to the 1/4 Renault Mégane Coupé (1/4 RMC) test car available in MIPS Laboratory (Mulhouse, France) (see in [8]), as given in Tab. IV.

TABLE IV

Parameter values of the Renault Mégane Coupé Quarter car MODEL

\begin{tabular}{lllll}
\hline Parameter & $m_{s}[\mathrm{~kg}]$ & $m_{u s}[\mathrm{~kg}]$ & $k_{t}[\mathrm{~N} / \mathrm{m}]$ & $k_{s}[\mathrm{~N} / \mathrm{m}]$ \\
Value & 315 & 37.5 & 29500 & 210000
\end{tabular}




\section{B. Performance criteria}

In general, the vehicle body acceleration between $0-20 \mathrm{~Hz}$ should be filtered to guarantee a good ride comfort, although it is worth noting again that the human is the most sensible to vertical acceleration around 4-8 Hz (ISO 2631). Besides, to maintain the road-wheel contact, it is necessary that the dynamic tire force is smaller than $g\left(m_{s}+m_{u s}\right)$ (where $g$ is the gravity). Hence, for the road holding improvement, the dynamic tire force $k_{t}\left(z_{u s}-z_{r}\right)$, in other words the dynamic tire deflection $z_{u s}-z_{r}$, should be small in the frequency range 0-30 Hz. Note also that the road holding is improved by limiting the up and down bouncing of the wheel $z_{u s}$ around its resonance $10-20 \mathrm{~Hz}$. With these remarks, the performance criteria $\left(J_{\text {Comfort }}\right.$ for comfort and $J_{\text {RoadHolding for road holding) }}$ in the frequency domain are explicitly described as follows

$$
\begin{aligned}
J_{\text {Comfort }} & =\min \int_{0}^{20} \ddot{z}_{s} / z_{r}(f) d f \\
J_{\text {RoadHolding }} & =\min \int_{0}^{30}\left(z_{u s}-z_{r}\right) / z_{r}(f) d f
\end{aligned}
$$

The objectives of the control design is to minimize both criteria that are consistent with the ones given in [1] and [2].

\section{C. $H_{\infty}$ problem}

In this paper, the suspension control problem is tackled in the $H_{\infty}$ framework. The control configuration for semi-active suspensions is given in Fig. 3. The controlled outputs are the vehicle body acceleration $\ddot{z}_{s}$ (for the ride comfort improvement) and the wheel displacement $z_{u s}$ (for the road holding improvement) (see [4]). The measurement outputs are the suspension deflection $z_{\text {def }}$ and suspension deflection velocity $\dot{z}_{\text {def }}$. To obtain the desired closed-loop performances, the weighting functions on controlled outputs $\left\{W_{\ddot{z}_{s}}, W_{z_{u s}}\right\}$ and disturbance input $W_{z_{r}}$ are considered.

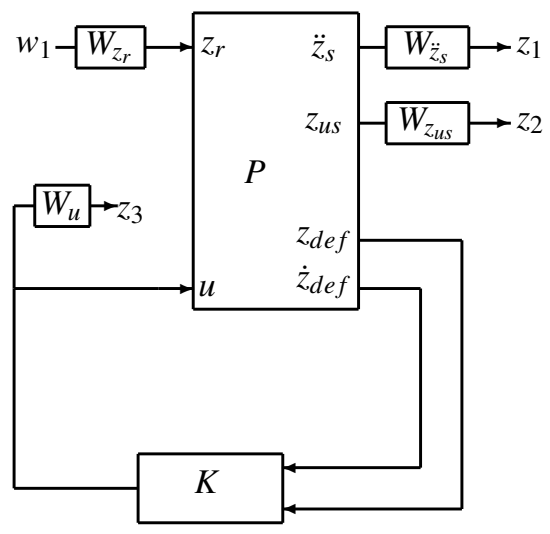

Fig. 3. LPV control scheme.

$$
\begin{aligned}
W_{z_{r}} & =3 \times 10^{-2} \\
W_{\ddot{z}_{s}} & =k_{\ddot{z}_{s}} \frac{s^{2}+2 \xi_{11} \Omega_{11} s+\Omega_{11}^{2}}{s^{2}+2 \xi_{12} \Omega_{12} s+\Omega_{12}{ }^{2}} \\
W_{z_{u s}} & =k_{z_{u s}} \frac{s^{2}+2 \xi_{21} \Omega_{21} s+\Omega_{21}}{s^{2}+2 \xi_{22} \Omega_{22} s+\Omega_{22}{ }^{2}}
\end{aligned}
$$

Let us define the set of parameters

$$
v=\left[\begin{array}{llllll}
\Omega_{11,12} & \xi_{11,12} & k_{\ddot{z}_{s}} & \Omega_{21,22} & \xi_{21,22} & k_{z_{u s}}
\end{array}\right]^{T}
$$

which, in the sense of the optimization problem, is the decision vector.

\section{Controller optimization for semi-active suspensions}

It is well-known that the key step of the $H_{\infty}$ control design depends on the selection of the weighting functions, which is linked to the engineer skill and experience. In this section, one applies the optimization procedure for $H_{\infty} / L P V$ controller optimization for semi-active suspension control presented in [4]. Let us remark that the control objective is to minimize the frequency-dependent performance criteria (6)-(7) for closed-loop suspension systems, rather than to minimize its induced $\mathscr{L}_{2}-\mathscr{L}_{2}$ gain. For this reason, in the following, an LPV controller is sought that solves the following problem:

$$
\text { minimize } \quad \mathrm{J}^{\mathrm{D}}
$$

subject to LMI solution for $H_{\infty} / L P V$ in [6] and [4]

where

$$
\begin{aligned}
J^{D} & =\left[\begin{array}{c}
J_{\text {Comfort }}^{D} \\
J_{\text {RoadHolding }}^{D}
\end{array}\right] \\
J_{\text {Comfort }}^{D} & =\sum_{i=1}^{N_{v}} \alpha_{i} \int_{0}^{12}\left(\ddot{z}_{s} / z_{r}(f)_{i}\right) d f \\
J_{\text {RoadHolding }}^{D} & =\sum_{i=1}^{N_{v}} \alpha_{i} \int_{10}^{20}\left(z_{u s} / z_{r}(f)_{i}\right) d f
\end{aligned}
$$

Note that the bounds of the integrals are chosen to emphasize the frequency ranges where the comfort and road holding are the most significant. Note also that, in the equations above, " $\mathrm{D}$ " is used to differentiate these design objective functions with the ones in Section III-B and the index " $i$ " stands for the $i^{t h}$ vertex of the polytope, $N_{v}$ is the number of vertices of the considered polytope of the LPV system. The scalars $\alpha_{i}$ are weighting parameters satisfying $\alpha_{i} \geq 0$ and $\sum_{i=1}^{N_{v}} \alpha_{i}=1$.

It can be seen that the cost function (13) is not convex, so (12) is a nonconvex optimization problem which can be solved, for instance as in [4] using genetic algorithms.

Below, two control methodologies will be designed from models (2)-(5) or (3)-(5) in the $H_{\infty}$ framework for polytopic systems. Indeed some scheduling parameters will be used later, representing, in some sense, the damper non-linearities.

\section{DESIGN METHOd 1}

The design method presented in [3] is briefly recalled. First, from the linear model of damper (2), the damper force is decomposed as follows

$$
F_{\text {damper }}=c^{0} \dot{z}_{\text {def }}+F_{d}
$$

where $c^{0}=\left(c_{\min }+c_{\max }\right) / 2$ and $F_{d}$ is the additional force. According to this decomposition, the control design will be 
based on the following quarter car model, denoted as $\left(\Sigma_{c}\right)$,

$$
\left\{\begin{array}{l}
m_{s} \ddot{z}_{s}=-k_{s}\left(z_{s}-z_{u s}\right)-c^{0}\left(\dot{z}_{s}-\dot{z}_{u s}\right)-F_{d} \\
m_{u s} \ddot{z}_{u s}=k\left(z_{s}-z_{u s}\right)+c^{0}\left(\dot{z}_{s}-\dot{z}_{u s}\right)+F_{d}-k_{t}\left(z_{u s}-z_{r}\right) \\
\dot{F}_{d}=2 \pi \beta\left(F_{d_{i n}}-F_{d}\right)
\end{array}\right.
$$

where $\beta$ represents the band-width of the damper. In the next section, the $H_{\infty}$ control method will be used, which means that $F_{d_{i n}}=u^{\mathscr{H}_{\infty}}$ where $u^{\mathscr{H}_{\infty}}$ is the additional force provided by an $H_{\infty}$ controller.

The $\mathscr{H}_{\infty}$ control method for the semi-active suspension system (17) referred to as Method 1, is given as in Fig. 4. This is a particular case of the control scheme in Fig. 3. Due to the fact that the damper force $F_{\text {damper }}$ must be limited in the admissible region of a semi-active damper (dissipative domain), the amplitude of $F_{d}$ or $u^{H_{\infty}}$ must be limited as well. To deal with this problem, a weighting function $W_{u}(\rho)$ on the controller output signal $u^{H_{\infty}}$ is introduced:

$$
W_{u}(\rho)=\rho W_{u}
$$

where $\rho \in[\rho ; \bar{\rho}] \subseteq \mathbb{R}^{+}$and $W_{u}$ is a strictly proper LTI filter. The scheduling parameter $\rho$ is used here to mitigate the semiactiveness violation of the damper force (i.e the damper force must be limited in $\mathscr{D}$, see Fig. 1):

- when $\rho$ is high, $W_{u}(\rho)$ is large, therefore, it tends to attenuate the $u^{\mathscr{H}_{\infty}}$ signal.

- when $\rho$ is low, $W_{u}(\rho)$ is small, therefore, it does not attenuate the $u^{\mathscr{H}_{\infty}}$ signal.

Therefore, from a general point of view, $\rho$ may be viewed as an anti-windup signal, computed on the actuator model (controlled damper model), and is similar to a variable saturation. For that purpose, the following scheduling strategy $\rho(\varepsilon)$ is introduced:

$$
\begin{gathered}
\rho(\varepsilon):= \begin{cases}\frac{\rho}{\rho}+\frac{\bar{\rho}-\underline{\rho}}{\mu}(\varepsilon-\mu) & \text { if } \varepsilon<\mu \\
\frac{\bar{\rho}}{\bar{\rho}} & \text { if } \varepsilon>2 \mu \leq 2 \mu\end{cases} \\
\varepsilon=\left\|F_{\text {damper }}-F_{\text {damper }}^{\perp}\right\|_{2}
\end{gathered}
$$

$F_{\text {damper }}^{\perp}$ is the orthogonal projection of the design force $F_{\text {damper }}$ on the admissible region of a semiactive damper's force (see [3]), $\mu$ is a design parameter that modifies the dead-zone of the $\rho(\varepsilon)$ function.

The controller design and optimization procedure that solve the problem 12 presented in [4] can be established for Method 1 with the following parameter specifications: $W_{u}=\frac{2 \pi 50}{s+2 \pi 50}, \beta=100 \pi, \underline{\rho}=0.1, \bar{\rho}=1, \mu=100, \alpha_{1}=0$ (corresponding to the vertex $\rho=\rho$ ) and $\alpha_{2}=1$ (corresponding to the vertex $\rho=\bar{\rho}$ ). This means that only the performance of the closed-loop system associated with the more active controller $\left(W_{u}\right.$ is small) is taken into account in the performance objective.

\section{Design Method 2}

In this section, the LPV formulation and controller synthesis based on the model (3) presented in [9] and [4] are

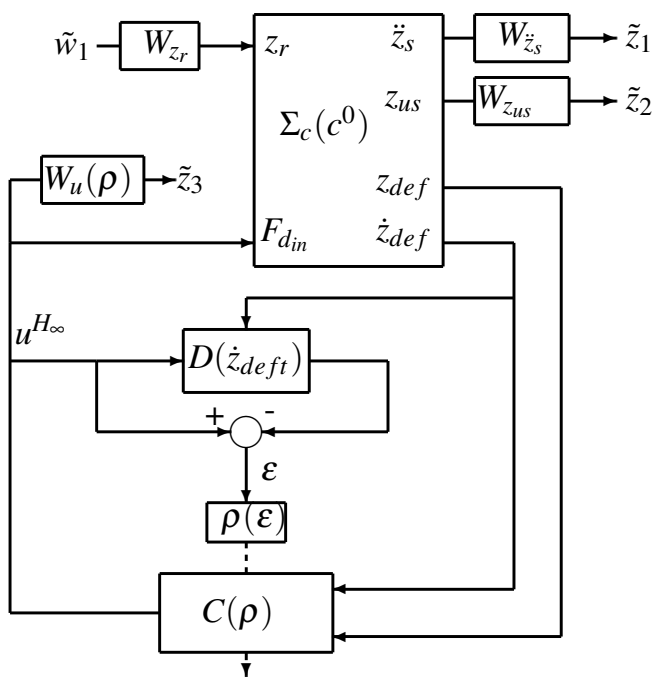

Fig. 4. Block diagram for semi-active suspension control: Method 1.

recalled. The dynamical equations corresponding to Fig. 2 (including the damper model (3)) are as follows

$$
\left\{\begin{array}{r}
m_{s} \ddot{z}_{s}=-k_{s}\left(z_{s}-z_{u s}\right)-c_{0}\left(\dot{z}_{s}-\dot{z}_{u s}\right)-k_{0}\left(z_{s}-z_{u s}\right) \\
-f_{I} \tanh \left(c_{1}\left(\dot{z}_{s}-\dot{z}_{u s}\right)+k_{1}\left(z_{s}-z_{u s}\right)\right) \\
m_{u s} \ddot{z}_{u s}=k_{s}\left(z_{s}-z_{u s}\right)+c_{0}\left(\dot{z}_{s}-\dot{z}_{u s}\right)+k_{0}\left(z_{s}-z_{u s}\right) \\
+f_{I} \tanh \left(c_{1}\left(\dot{z}_{s}-\dot{z}_{u s}\right)+k_{1}\left(z_{s}-z_{u s}\right)\right)-k_{t}\left(z_{u s}-z_{r}\right)
\end{array}\right.
$$

Denoting

$$
\begin{aligned}
\hat{\rho} & =\tanh \left(c_{0}\left(\dot{z}_{s}-\dot{z}_{u s}\right)+k_{0}\left(z_{s}-z_{u s}\right)\right) \\
u_{I} & =f_{I}-f_{0}
\end{aligned}
$$

where $f_{0}=\left(f_{\text {Imin }}+f_{\text {Imax }}\right) / 2$. The state-space representation of the quarter vehicle is given as follows:

$$
P:\left\{\begin{array}{l}
\dot{x}_{s}=\left(A_{s}+B_{s 1} \frac{\hat{\rho}}{C_{s 1} x_{s}} C_{s 1}\right) x_{s}+B_{s} \hat{\rho} \frac{\text { sat }\left(u_{I}\right)}{u_{I}} u_{I}+B_{s w} w \\
z=\left(C_{s z}+D_{s 1} \frac{\hat{\rho}}{C_{s 1} x_{s}} C_{s 1}\right) x_{s}+D_{s z} \hat{\rho} \frac{\text { sat }\left(u_{I}\right)}{u_{I}} u_{I} \\
y=C_{s} x_{s}
\end{array}\right.
$$

where $x_{s}=\left(z_{s}, \dot{z}_{s}, z_{u s}, \dot{z}_{u s}\right)^{T}, w=z_{r}$,

$$
\begin{aligned}
& y=\left(z_{s}-z_{u s}, \dot{z}_{s}-\dot{z}_{u s}\right)^{T}, z=\left(\begin{array}{ll}
\ddot{z}_{s} & z_{u s}
\end{array}\right)^{T} . \\
& A_{s}=\left(\begin{array}{cccc}
0 & 1 & 0 & 0 \\
-\frac{k_{p}}{m_{s}} & -\frac{c_{p}}{m_{s}} & \frac{k_{p}}{m_{s}} & \frac{c_{p}}{m_{s}} \\
0 & 0 & 0 & 1 \\
\frac{k_{p}}{m_{u s}} & \frac{c_{p}}{m_{u s}} & -\frac{k_{p}+k_{t}}{m_{u s}} & -\frac{c_{p}}{m_{u s}}
\end{array}\right) \text {, } \\
& B_{s}=\left(\begin{array}{c}
0 \\
-\frac{1}{m_{s}} \\
0 \\
\frac{1}{m_{u s}}
\end{array}\right), B_{s w}=\left(\begin{array}{c}
0 \\
0 \\
0 \\
\frac{k_{t}}{m_{u s}}
\end{array}\right) \text {, } \\
& B_{s 1}=\left(\begin{array}{c}
0 \\
-\frac{f_{0}}{m_{s}} \\
0 \\
\frac{f_{0}}{m_{u s}}
\end{array}\right), C_{s}=\left(\begin{array}{cc}
1 & 0 \\
0 & 1 \\
-1 & 0 \\
0 & -1
\end{array}\right) \text {, } \\
& C_{s z}=\left(\begin{array}{cccc}
\frac{-k_{p}}{m_{s}} & \frac{-c_{p}}{m_{s}} & \frac{k_{p}}{m_{s}} & \frac{c_{p}}{m_{s}} \\
0 & 0 & 1 & 0
\end{array}\right), D_{s z}=\left(\begin{array}{c}
\frac{-1}{m_{s}} \\
0
\end{array}\right)
\end{aligned}
$$


$C_{s 1}=\left(\begin{array}{llll}k_{1} & c_{1} & -k_{1} & -c_{1}\end{array}\right), D_{s 1}=\left(\begin{array}{cc}\frac{-f_{0}}{m_{s}} & 0\end{array}\right)$

$\operatorname{sat}\left(u_{I}\right)$ is the saturated function of $u_{I}$ and takes values in $\left[-\left(f_{\text {Imax }}-f_{\text {Imin }}\right) / 2,\left(f_{\text {Imax }}-f_{\text {Imin }}\right) / 2\right]$.

In [4], the model (24) is transformed into the following LPV model:

$$
\left\{\begin{array}{l}
\dot{x}=A\left(\rho_{1}, \rho_{2}\right) x+B u+B_{1} w \\
z=C_{z}\left(\rho_{1}, \rho_{2}\right) x \\
y=C x
\end{array}\right.
$$

with $x=\left(\begin{array}{ll}x_{s}{ }^{T} & x_{f}{ }^{T}\end{array}\right)^{T}$ where $x_{f}$ represents the state of the filter, needed to make the generalized plant consistent with the $H_{\infty}$ design problem for polytopic systems [5].

$$
W_{f}:\left(\begin{array}{c}
\dot{x}_{f} \\
u_{I}
\end{array}\right)=\left(\begin{array}{cc}
A_{f} & B_{f} \\
C_{f} & 0
\end{array}\right)\left(\begin{array}{c}
x_{f} \\
u
\end{array}\right)
$$

with $\left\|W_{f}\right\|_{\infty} \leq 1, A_{f}, B_{f}, C_{f}$ being constant matrices, and

$$
\begin{aligned}
& A\left(\rho_{1}, \rho_{2}\right)=\left(\begin{array}{cc}
A_{s}+\rho_{2} B_{s 1} C_{s 1} & \rho_{1} B_{s} C_{f} \\
0 & A_{f}
\end{array}\right), \\
& B=\left(\begin{array}{c}
0 \\
B_{f}
\end{array}\right), B_{1}=\left(\begin{array}{c}
B_{s 1} \\
0
\end{array}\right), C=\left(\begin{array}{c}
C_{s} \\
0
\end{array}\right)^{T} \text {, } \\
& C_{z}\left(\rho_{1}, \rho_{2}\right)=\left(\begin{array}{ll}
C_{s z}+\rho_{2} D_{s 1} C_{s 1} & \rho_{1} D_{s z} C_{f}
\end{array}\right) \\
& \rho_{1}=\tanh \left(C_{s 1} x_{s}\right) \frac{\operatorname{sat}\left(c_{f} x_{f}\right)}{c_{f} x_{f}}, \rho_{2}=\frac{\tanh \left(C_{s 1} x_{s}\right)}{C_{s 1} x_{s}}
\end{aligned}
$$

The control configuration for semi-active suspensions is given in Fig. 5. This configuration is very similar to the one used by Method 1 (in this case $W_{u}$ is set to 0 ).

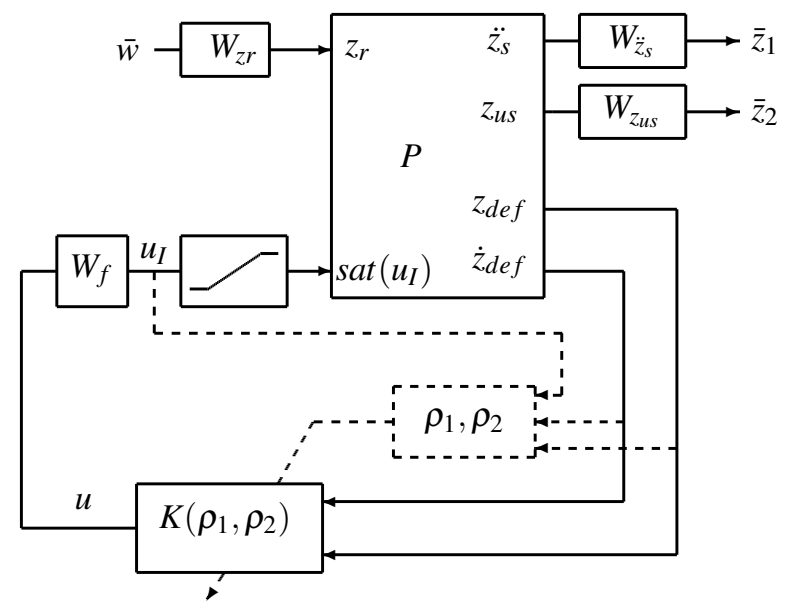

Fig. 5. Block diagram for semi-active suspension control: Method 2

The controller design and optimization procedure presented in [4] is once again applied for Method 2. The complete results for Method 2 are given in [4]. Notice that, due to the self-dependence between $\rho_{1}$ and $\rho_{2}$, the set of all $\bar{\rho}=\left(\rho_{1}, \rho_{2}\right)$ is not a polytope. In this study, a polytopic approach is developed for the LPV control design (which leads to some conservatism). As a consequence, $\rho_{1}$ and $\rho_{2}$ are considered as independent parameters and $\bar{\rho}$ belongs to a polytope $\Theta$ whose vertices are $\bar{\rho}_{1}=(-1,0), \bar{\rho}_{2}=(1,0)$, $\bar{\rho}_{3}=(1,1), \bar{\rho}_{4}=(-1,1)$.

\section{NUMERICAL ANALYSIS AND RESULTS}

Some simulation results are presented to emphasize the interest and the possible limitations of both methodologies for the best comfort-oriented controllers of Method 1 and Method 2 (i.e only $J_{\text {Comfort }}^{D}$ is considered in the optimization problem 12). In what follows, because the outputs of the controllers obtained in Method 1 and Method 2 are forces, the desired current $I$ is reconstructed for each method in order to be used in model (1) for simulation of MR damper: For method 1: Since the damper model is not included in the controller design, an inverse damper model is needed to regenerate the input current. In this study, with the good approximation to real data, the model (3) is used as the inverse model, i.e the input current will be recovered by the following equation (note that the input current must be limited in $\left[0, f_{I \max } / y_{m r}\right]$ (see Section II-B)):

$$
I=\frac{u^{H_{\infty}}+c^{0} \dot{z}_{d e f}-c_{0} \dot{z}_{d e f}-k_{0} z_{d e f}}{y_{m r} \tanh \left(c_{1} \dot{z}_{d e f}+k_{1} z_{d e f}\right)}
$$

For method 2: Since the damper model is taken into consideration in the controller design, the input current is simply computed from the controller output $u_{I}$ by using the equations (4) and (23):

$$
I=\frac{u_{I}+F_{0}}{y_{m r}}
$$

Below the comparison is completed by simulations of the following passive MR dampers: Soft MRD $\left(f_{I}=f_{\text {Imin }}\right)$, Hard $\operatorname{MRD}\left(f_{I}=f_{\text {Imax }}\right)$, Nominal MRD $\left(f_{I}=\left(f_{\text {Imin }}+f_{\text {Imax }}\right) / 2\right)$.

\section{A. Frequency domain analysis}

In this section, the evaluation in the frequency domain is performed via the nonlinear frequency response of $\ddot{z}_{s}$ that is computed by the "Variance Gain" algorithm [10] (where the input $z_{r}$ is chosen to be a sinusoidal signal with magnitude of $1.5 \mathrm{~cm}$ and frequency varying in [0.1-30] $\mathrm{Hz}$ ). This algorithm is simple and provides a good approximation to the nonlinear frequency response.

Some general remarks can be drawn for passive MR dampers (see [4]):

- Between $0-2 \mathrm{~Hz}$, the Hard MRD is the best strategy for ride comfort.

- Between 2-30 Hz, the Soft MRD is the best strategy for ride comfort.

As seen in Fig. 6, both LPV controllers largely improve the passenger comfort w.r.t passive cases. When compared between each other, the LPV Method 1 is slightly better in medium frequencies but lightly worse in high frequencies and low frequencies than the LPV Method 2.

\section{B. Time domain analysis}

Test 1: Step road profile In this test, the road profile $z_{r}$ is a step signal (the amplitude is $10 \mathrm{~cm}$ and the starting time is $t_{0}=1 \mathrm{~s}$ ) filtered beyond $30 \mathrm{~Hz}$. The car body acceleration responses are depicted in Fig. 7. The results show that: 
The peak values around the starting time (1s) are small for the cases of Soft MRD, Method 1 and Method 2 while they are larger for Nominal MRD and Hard MRD. The damping behavior (the convergence to zero) is the best in the case of Hard MRD. The Method 2 and Nominal MRD provide a good damping behavior as well. The Method 1 is a little worse compared to the Method 2 and the Soft MRD give the worst damping capacity. The use of LPV controllers reduce the peak values as well as the RMS values of the car body acceleration. They provide a better comfort improvement w.r.t passive dampers.

Test 2: Random road profile The road profile can also be viewed as a random signal, because it is not predicted by the vehicle. However, in practice, its bandwidth is limited. In this test, a road profile is represented by an integrated white noise, band-limited within the frequency range [0-30] $\mathrm{Hz}$.

The comfort is evaluated using the RMS value of the car body acceleration. The comparison of the RMS values is depicted in Fig. 8. It confirms again the efficiency of LPV approaches to improve the comfort of automotive suspension systems equipped with an MR damper. In this case, the LPV controllers give the same results.

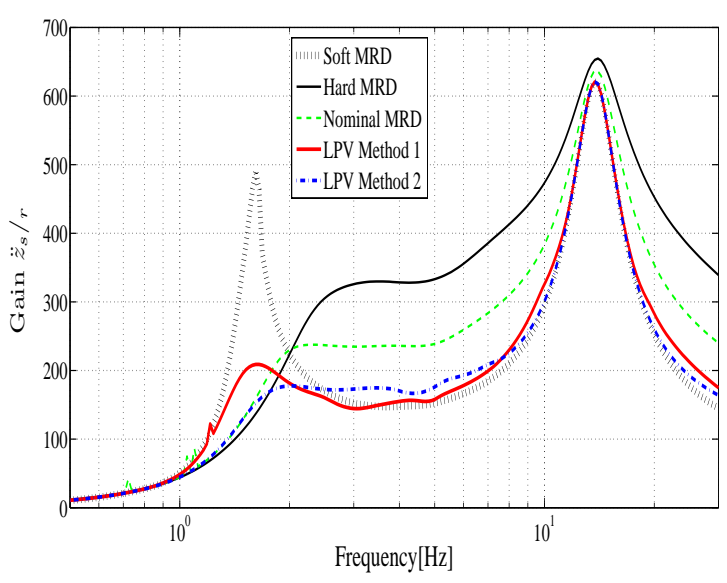

Fig. 6. Frequency responses comparison.

\section{CONCLUSION}

In this paper, the illustration of two LPV control methods for automotive suspension systems equipped with MR dampers has been done. The two main contributions of the paper may be summarized as follows: the proposed control schemes are homogenous to ensure a fair comparison between two methods, the application (synthesis and implementation) of the LPV approach proposed by [3] and [4] on nonlinear MR damper. The simulations on the nonlinear quarter vehicle model equipped with a validated MR damper (in both frequency and time domains) have shown the interest of LPV design in semi-active suspension control.

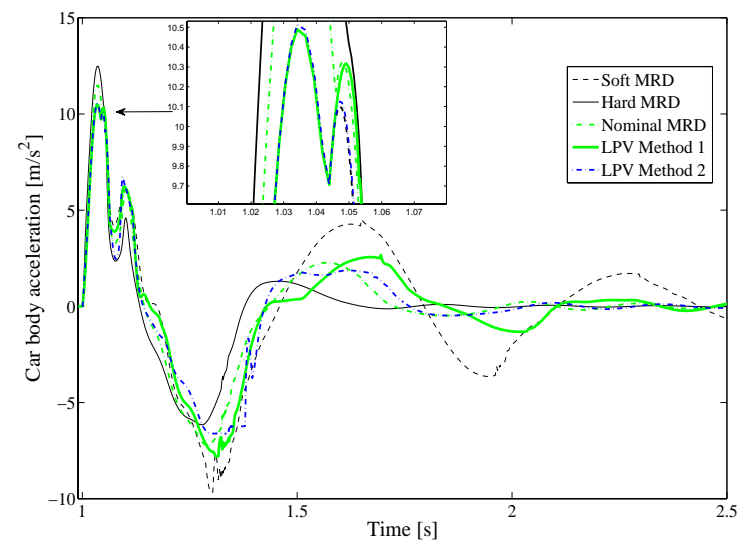

Fig. 7. Step responses comparison.

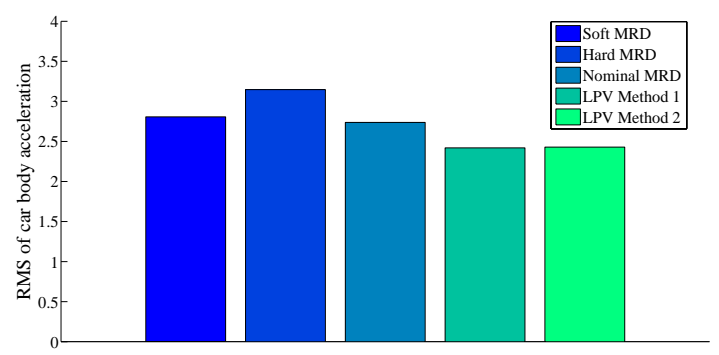

Fig. 8. RMS values of car body acceleration.

\section{REFERENCES}

[1] S. Savaresi, C. Poussot-Vassal, C. Spelta, O. Sename, and L. Dugard, Semi-Active Suspension Control for Vehicles, ser. 978-0-08-096678-6. Elsevier, London 2010.

[2] D. Sammier, O. Sename, and L. Dugard, "Skyhook and $\mathscr{H}_{\infty}$ control of active vehicle suspensions: some practical aspects," Vehicle System Dynamics, vol. 39, no. 4, pp. 279-308, april 2003.

[3] C. Poussot-Vassal, O. Sename, L. Dugard, P. Gáspár, Z. Szabó, and J. Bokor, "New semi-active suspension control strategy through LPV technique," Control Engineering Practice, vol. 16, no. 12, pp. 15191534, December 2008.

[4] A. L. Do, O. Sename, and L. Dugard, "LPV modelling and control of semi-active dampers in automotive systems," in Control of Linear Parameter Varying Systems with Applications, Mohammadpour and C. Scherer, Eds. Springer, 2012, ch. 15.

[5] P. Apkarian and P. Gahinet, "A convex characterization of gain scheduled $\mathscr{H}_{\infty}$ controllers," IEEE Transaction on Automatic Control, vol. 40, no. 5, pp. 853-864, may 1995.

[6] C. Scherer, P. Gahinet, and M. Chilali, "Multiobjective outputfeedback control via LMI optimization," IEEE Transaction on Automatic Control, vol. 42, no. 7, pp. 896-911, july 1997.

[7] J. J. Lozoya-Santos, J. A. Ruiz-Cabrera, R. Morales-Menéndez, R. Ramírez-Mendoza, and V. Diaz-Salas, "Building training patterns for modelling MR dampers," in ICINCO-SPSMC, 2009, pp. 156-161.

[8] A. Zin, "Robust automotive suspension control toward global chassis control," PhD Thesis (in French), INPG, Laboratoire d'Automatique de Grenoble (new GIPSA-lab), Grenoble, France, October 2005.

[9] A. L. Do, O. Sename, and L. Dugard, "An LPV control approach for semi-active suspension control with actuator constraints," in Proceedings of the IEEE American Control Conference (ACC), Baltimore, Maryland, USA, June 2010.

[10] S. Savaresi, S. Bittanti, and M. Montiglio, "Identification of semiphysical and black-box models: the case of MR-dampers for vehicles control," Automatica, vol. 41, pp. 113-117, 2005. 